\title{
Renascidas no Brasil: Ruth Escobar, Leonor Xavier e a imigração como reinvenção
}

\author{
Mario Luis Grangeia \\ Escola Superior do Ministério Público da União
}

\begin{abstract}
Resumo
A imigração teve papel central nas vidas de Ruth Escobar (1935-2017) e Leonor Xavier (1943-). Nascida em Campanhã (Porto), Ruth fixou-se aos 16 anos com a mãe em São Paulo e se tornou atriz, produtora teatral e líder feminista. Leonor saiu de Lisboa em 1975 com o marido e os três filhos e viveu até 1987 em São Paulo e no Rio de Janeiro, onde se revelou jornalista e escritora. Reconhecidas em suas áreas e por contribuições aos diálogos culturais entre Brasil e Portugal, elas publicaram autobiografias com olhares singulares da imigração portuguesa no Brasil e seus efeitos em suas trajetórias. Tais representações estão no foco desta análise de conteúdo das duas autobiografias.
\end{abstract}

Palavras-chave: portuguesas no Brasil; Ruth Escobar; Leonor Xavier; autobiografia; imigração.

\begin{abstract}
Immigration played a central role in the lives of Ruth Escobar (1935-2017) and Leonor Xavier (1943-). Born in Campanhã (Porto), Ruth settled at 16 with her mother in São Paulo and became an actress, theatrical producer and feminist leader. Leonor left Lisbon in 1975 with her husband and three children and lived until 1987 in São Paulo and Rio de Janeiro, where she became a journalist and writer. Recognized in their fields and for contributions to cultural dialogues between Brazil and Portugal, they published autobiographies with unique views of Portuguese immigration in Brazil and their effects on their trajectories. Such representations are in the focus of this content analysis of the two autobiographies.
\end{abstract}

Keywords: Portuguese women in Brazil; Ruth Escobar; Leonor Xavier; autobiography; immigration.

Recebido em: 30/07/19

Aprovado em: $16 / 11 / 19$

As emoções só se podem dizer por palavras, se perdemos as palavras acabamos por perder os sentimentos que elas exprimem, haverá um isolamento interior, ficamos incomunicáveis. Escrevemos onde temos que escrever, nem que seja na ponta de uma agulha. (SARAMAGO apud XAVIER, 2018, p. 356)

"Este é o meu presente para Portugal", afirmou a produtora teatral e atriz Ruth Escobar após entrevista à jornalista Leonor Xavier no Centro Cultural de Belém (CCB), em Lisboa, em 
2002. Seu presente era a montagem de Os Lusíadas com 42 atores e três toneladas de cenários e figurinos do Brasil (XAVIER, 2016). A atriz nasceu em Campanhã (Porto), viveu 65 anos em São Paulo e revia ali uma jornalista que tinha conhecido em 1985. O reencontro deu chance a Ruth de divulgar o espetáculo e, sobretudo, avaliar sua vida para a jornalista lisboeta, que viveu em São Paulo e Rio de Janeiro de 1975 a 1987.

Entre seu primeiro contato e o reencontro em Lisboa, elas publicaram livros com histórias suas (a autobiografia Maria Ruth, de 1987) e de terceiros (Falar de viver, livro de entrevistas de Leonor, de 1986) e deram guinadas em suas vidas - a atriz se dedicara à política e a jornalista voltara a Lisboa, onde continuaria "a escrever sobre Portugal no Brasil e sobre o Brasil em Portugal" (XAVIER, 2016). A conversa às vésperas da estreia de Os Lusíadas foi relatada em Portugueses do Brasil e Brasileiros de Portugal (2016), com extratos de 18 entrevistas da jornalista com artistas que uniram aqueles dois países.

As autobiografias Maria Ruth, publicada no Brasil, e Casas contadas, lançada por Leonor em Portugal, são foco de uma análise de conteúdo que privilegia memórias de suas raízes portuguesas e da adaptação ao solo brasileiro. Este artigo discute como as autoras viram na imigração uma reinvenção de suas identidades. Eis um desdobramento de pesquisas apoiadas pelo Centro Nacional de Cultura (CNC, Portugal) e Fundação Biblioteca Nacional (Brasil) sobre olhares de empreendedores e escritores à imigração portuguesa no Brasil focos raramente estudados. Segundo Lobo (2001), acadêmicos em Portugal pesquisaram mais o período até 1930, os perfis de emigrantes, o impacto da migração para Portugal e o estímulo na circulação comercial e de capital, enquanto predominaram no Brasil trabalhos estatísticos, sobre o papel do imigrante na economia e na sociedade brasileiras, sobre a rivalidade entre os dois povos e a imagem recíproca.

Ruth Escobar (1935-2017) emigrou em 1951 com a mãe Marília, que dizia partir em busca de um futuro melhor para ela, nascida de uma relação extraconjugal do pai. Em São Paulo, tornou-se atriz e produtora teatral, foi a primeira presidente do Conselho Nacional dos Direitos das Mulheres (1985-1986) e, ao morrer, a ONU Mulheres frisou sua "obstinada trajetória política, feminista e cultural", além do "legado a ser valorizado por todas as brasileiras e brasileiros" (GASMAN, 2017). Sua entrada na política (foi deputada estadual de 1983 a 1991) pode ser lida à luz de uma visão de sua compatriota Agustina Bessa-Luís em Falar de viver (XAVIER, 1986). Após diagnosticar o despertar da consciência de grande nação do Brasil em sua transição democrática, comentou que "se eu fosse brasileira, talvez descobrisse em mim uma vocação política, pela grandeza dos problemas a resolver. Isso é tão sedutor. São caminhos a abrir, que não se limitam por ideologias" (Agustina Bessa-Luís apud XAVIER, 1986, p. 10). Ruth abriu seu caminho.

Leonor Xavier emigrou em 1975, aos 31 anos, com seus filhos Leonor, Maria e Gonçalo e o marido Alberto, secretário de Estado do Planeamento quando da Revolução dos Cravos. 
Licenciada em Filologia Românica, foi correspondente do jornal Diário de Notícias no Rio de Janeiro e escreveu para outros jornais e revistas. Em seus textos, "procura ela alargar - e se possível reforçar - a ponte entre brasileiros e portugueses", disse o jornalista Mário Pontes na orelha de Falar de viver. No prefácio, o escritor António Alçada Batista frisou que foi no Brasil que Leonor se revelou jornalista e escritora: "É possível que, se ela aqui tivesse permanecido, não pudesse manter escondido o seu talento literário mas estou certo de que ela o não teria revelado com a desenvoltura de pensamento, de escrita e de empenhamento com que o fez no Brasil” (BAPTISTA, 1986, p. IX). Sua autobiografia reconstitui memórias a partir das 13 casas que chamou de suas, incluindo o atual endereço em Lisboa onde conversou com este autor. ${ }^{1}$

A alusão de Agustina Bessa-Luís à fertilidade para a vida política no Brasil pós-ditadura e a de António Alçada Baptista sobre a influência do país na expressão literária de Leonor remetem ao papel que contextos podem ter em vidas e obras. Discutir olhares das autobiografias das duas portuguesas à imigração e ao país adotado — de vez ou num período — permite refletir sobre seus laços com aquele processo histórico e seu território.

\section{Ruth Escobar e sua reinvenção no Brasil: "em mim se misturavam a excitação e a dor"}

Quando Maria Ruth fingia desmaios para sair da detestada aula de inglês, já se apegara ao palco encenando os diabos de Gil Vicente no liceu, no Porto, ou divertindo-se com amigas imitando Carmem Miranda em "Mamãe eu quero mamar" e "Tico-tico no fubá". A mãe, amante do pai ignorado por Ruth, planejava a ida delas ao Brasil atrás de futuro melhor. Os desmaios fingidos poderiam fazer a professora de inglês não crer nela ("pois sim, no dia em que voltar D. Sebastião [rei morto em batalha de 1578]"), mas ali não era farsa. Aos 16 anos, a travessia do Atlântico soava uma jornada remota - "emigrar para a América ou para o Brasil era repetir a façanha dos navegadores no século XX” (ESCOBAR, 1987, p. 29) - , mas viveu-a com dor e excitação, como lembraria:

Quando embarquei para o Brasil no Serpa Pinto, com minha mãe, levava também a certeza de um destino, pois senti que tudo quando sucedera em minha vida, mesmo antes do nascimento, estava moldado por uma força universal, cósmica, transcendente. A cena do adeus no cais do porto foi digna de qualquer filme de Lana Turner, recorde mundial de lágrimas. Minha mãe se debulhava ao meu lado. Meu padrasto, pela primeira vez, tinha os olhos vermelhos de chorar, e a noção assimilada de que homem não chora me fez sentir em dobro a dor que ele atravessava. Em mim se misturavam a excitação e a dor. Certamente, para os que ficaram no cais de Leixões, a dor foi bem mais intensa, até porque não partilhavam da excitação de quem ia rumo à América do Sul. (ESCOBAR, 1987, p. 34)

\footnotetext{
${ }^{1}$ Sou grato a Alexandra Prista, do CNC, por me colocar em contato com a escritora.
} 
A dor foi dividida com quem ficou, como Jacqueline, amiga com quem viveu o primeiro romance e em cuja casa apaziguara a rejeição sofrida na infância. Os primeiros endereços paulistanos de Ruth e sua mãe foram nos fundos de um bar no Tatuapé, duas semanas cruzando bêbados cheirando mal para irem dormir, e num quarto de empregada no Ipiranga, onde o banheiro era no corredor, com chuveiro frio, e cozinhavam com um fogareiro no quarto. Puderam alugar um dois-quartos no Pari quando a mãe conseguiu trabalho de costureira e Ruth dividiu o estudo com a venda de anúncios da Revista das Indústrias, onde usaria os dons teatrais. "Estou trabalhando para ajudar minha mãezinha doente", dramatizava a jovem (MENDES, 1981, p. 45). Meses depois, decidiu editar sua revista, para a colônia portuguesa e com notícias de alémmar e da comunidade. Chamava-se Ala Arriba em alusão ao grito de pescadores ao tirarem do mar redes com peixe. Menor de idade, não podia ter empresa. Estrangeira, era proibida de editar qualquer publicação.

Como ainda faria 18 anos, conseguiu um responsável e um editor para a Gráfica Cinelândia rodar a primeira edição; isso após mostrar contratos de publicidade fechados para pagá-la. "Acho que também contei com uma certa proteção da colônia portuguesa, que via espantada aquela 'miúda espevitada' aventurar-se a uma tarefa tão pouco própria de mulheres”, notou, citando papel da rede de imigrantes (ESCOBAR, 1987, p. 36).

Enquanto Ruth vivia dores e excitações em terra firme, a mãe via na imigração um sacrifício pela filha e seu futuro, como disse ao armar o vestido do baile da coroação de Ruth rainha do colégio: "criei-te com sacrifício da minha própria vida, abandonei teu pai para dar-te um futuro no Brasil. Depois de tudo, não vais desapontar tua mãezinha que fez tudo para te criar em berço de ouro" (ESCOBAR, 1987, p. 37). A mãe era julgada castradora ainda por temer que ela se enamorasse sem resistir à "tentação do demônio".

O início de sua saga no Brasil foi como uma reinvenção, dadas suas mudanças íntimas e físicas. A aspirante a atriz se casou aos 18 anos com o francês J. (assim citado) mais por um gesto solidário do arquiteto-desenhista e colega de trabalho para tirá-la do convívio com a mãe repressora, que lhe provocava a vontade de fugir e até se suicidar.

É claro que senti o choque de ter deixado em Portugal a aparente segurança de uma vida rotineira, embora não isenta de incidentes nem sempre agradáveis. Por outro lado, animava-me a sensação de conquistar uma nova forma de existir, com todas as suas crueldades e dificuldades, mas também com todo o seu desafio. As mudanças se faziam visíveis a mim mesma, tanto no íntimo como no físico: sabia-me mais solta, no meu andar, mais ágil, mais moderninha. Não me sentia mais tão forçada a me esconder nas sobras de meus complexos de feiúra por ter as coxas grossas, as sobrancelhas cerradas e o buço de saloia. (ESCOBAR, 1987, p. 40)

A autoestima e a sensação de liberdade e modernidade só cresciam. A reinvenção foi impulsionada ao se afastar da mãe, que se despediu no trem para as núpcias em Rio Claro 
beijando-a e chorando "como se eu estivesse indo para o matadouro" (ESCOBAR, 1987, p. 43). Ao visitar Portugal, foi indagar à professora de inglês se D. Sebastião tinha voltado, pois ela estava há dois anos no Brasil - revidava o que julgou uma humilhação.

Partiu de São Paulo o voo mais longo e decisivo para ela, separada após um caso com um polonês. Era 1954, tinha 18 anos e viajava à Ásia com planos de trazer notícias da defesa portuguesa nas colônias na Índia, onde havia rumores de independência - a viagem foi patrocinada em parte pela cervejaria Caracu, cujos anúncios na Ala Arriba chegavam a mais de 2 mil bares e armazéns de portugueses; pagaria o valor restante com matérias freelance e a venda de poucos móveis e seu apartamento na avenida São João.

O roteiro ligou Nova York, Los Angeles, Tóquio, Hong Kong, Macau, Saigon - onde fez câmbio ilegal e comprou a volta via Lisboa por $25 \%$ do valor -, Phonon Penh (Camboja), Bangkok e Karachi, de onde foi até a Índia Portuguesa (Goa, Diu e Damão). Mais de 30 anos depois, avaliou: "olho para trás. Curiosa e perplexa, não consigo entrar na pele daquela menina portuguesa atravancada de complexos, mas absolutamente determinada a virar a mesa e inventar um destino pela soma de todas as transgressões" (ESCOBAR, 1987, p. 53). Em Saigon, marcoulhe a visão confucionista sobre as mulheres, permitindo-se fazer paralelo com a visão da mulher "enquadrada na completa tutela do homem" em Portugal nos tempos de Salazar (ESCOBAR, 1987, p. 65). Encontrou o ditador na volta, sob o pretexto de entregar a foto autografada pelo príncipe de Camboja - por ideia dela. Após ouvir suas histórias, Salazar lhe recomendaria: "continue portuguesa".

A autora atribuiu a suas raízes a capacidade de viver meses como cigana: "estava cansada de ser cigana. Não sabia ainda que é assim mesmo que se é lusitana, pois então era só ao Portugal que debitava os fragmentos que sentia ser. Percebia que algo de novo, profundo, crucial, se instilara em sua alma" (ESCOBAR, 1987, p. 72). A estada no Extremo Oriente foi um divisor de águas para Ruth (dos Santos, à época), que desistiu do plano de reencontrar o namorado polonês e formarem família.

Ruth voltou a São Paulo mais cosmopolita, mas sua origem foi retomada ao citar a ideia de ter um teatro: "Não seria um teatro, mas um exorcismo. Tumba e monumento, mausoléu e palácio, pecado e redenção, amor de perdição - amor de salvação. Não se nasce português impunemente" (ESCOBAR, 1987, p. 110). Assim como sua admiração ao diretor Victor Garcia: "Lia-me por dentro, cutucava minha loucura, minha ambição e meus delírios, bem como meus pudores de menina portuguesa" (ESCOBAR, 1987, p. 125). Portanto, ligava suas raízes a um senso de comunidade (imaginou comendadores e outros portugueses investindo em seu teatro) e uma identidade estrangeira que a diferenciava na classe artística; ora a origem lhe trazia laços, ora lhe distinguia.

Exploraria seus vínculos comunitários ao captar fundos para construir seu teatro. "Dei um cheque sem fundos de 500 cruzeiros, como sinal, e pedi ao dono que esperasse quinze 
dias para descontá-lo. Peguei um livrinho de ouro e saí pela colônia portuguesa levantando o dinheiro. Eu não estou convencida de que a colônia acreditasse, na época, que eu fosse conseguir", contou à Folha de S. Paulo, que a nominou "Rute" (MENDES, 1981, p. 45). A parceria com Cacilda Becker, escreveria ela, deu o respeito dos pares de que carecia como "portuguesa, sem escola de arte dramática, sem carteirinha do partidão" (ESCOBAR, 1987, p. 123). A nacionalidade perderia espaço em imagens correntes sobre Ruth, mas não foi esquecida no capítulo sobre os movimentos sociais com portugueses no livro Presença portuguesa em São Paulo, do Memorial do Imigrante (FREITAS, 2006), com perfis de Ruth e da também atriz portuguesa Maria Prestes Maia, ambas engajadas no feminismo.

Quando Ruth conheceu Leonor Xavier, em 1985, tinha cinco filhos, sobrenome artístico herdado de um ex-marido (o filósofo Carlos Henrique Escobar) e seu teatro tinha 19 anos, período em que fez espetáculos ousados nas ditaduras no Brasil e Portugal. Em 2002, a atriz frisou a dificuldade de uma portuguesa revolucionar o teatro no Brasil: "Nos brasileiros, há uma necessidade de fazer troça dos portugueses, há um preconceito, diz-se que o português é ignorante por causa do nosso tipo de colonização. Por isso, muitas vezes fui agressiva a defender o meu trabalho" (ESCOBAR apud XAVIER, 2016, p. 177). O ativismo feminista foi ressaltado por Leonor: "No Brasil, onde o poder masculino é absoluto, Ruth Escobar tem sido uma das personalidades mais envolvidas na denúncia da situação das mulheres e na alteração das mentalidades" (XAVIER, 2016, p. 177).

A volta às raízes era uma pauta sua naquela releitura de Os Lusíadas: "a ida do homem à Lua é um incidente, comparada com a grandiosidade dos portugueses na descoberta de outros mundos. [...] Não sei como me deu a vontade de fazer este espetáculo, foi uma coisa estranha, muito forte, como se eu quisesse agora reafirmar a minha lusitanidade" (ESCOBAR apud XAVIER, 2016, p. 174). Essa volta fechava-se na compra de um lar no país natal, apesar de preservar o estranhamento sobre Portugal, por ter a impressão de que os portugueses tinham perdido suas raízes. Ela retomava as suas nessa montagem, que foi seu último trabalho no teatro.

\section{Leonor Xavier e reinvenção na imigração: "grande revolução foi a chegada ao Brasil"}

Com a restauração da democracia em Portugal em 1974, as mudanças se fizeram sentir nos meses seguintes - alguns portugueses sentindo mais do que outros. Foi o caso da família do advogado Alberto Xavier, professor de Direito da Universidade de Lisboa e titular da Secretaria de Estado do Planeamento nos 40 dias anteriores à Revolução dos Cravos. Afastado do cargo docente, ele, a esposa Leonor e os três filhos emigraram para São Paulo em março de 1975 — a família soube o destino com três dias de antecedência. Os pais de Leonor pagaram as passagens dos voos de Lisboa para São Paulo via Paris. 
Começava assim “a grande guinada de minha vida", segundo Leonor, que não trabalhava à época. A falta de conhecimento e planejamento se vê na hesitação das roupas a levar: "sem noção do frio ou do calor, da chuva ou do bom tempo que iríamos descobrir naquele outro lado do mundo totalmente desconhecido para mim, e distante de toda a minha imaginação até ao momento em que soube e obedeci à ordem de partida" (XAVIER, 2018, p. 107). Note-se a condição subalterna da esposa ao dizer que obedeceu.

$\mathrm{Na}$ autobiografia, recordou a curta viagem ao Brasil cinco anos antes, a convite do pai, que foi para um congresso de radiologia no Rio de Janeiro. O marido pagou a passagem dele e a estada do casal em hotel na orla de Copacabana. Na praia, marcou-lhe ver um negro vendedor de abacaxis forte e belo anunciando a fruta quase cantando. Ignorava a repressão política, tortura e censura no início do governo Médici - viram no Teatro Ruth Escobar, em São Paulo, a montagem de $O$ balcão, de Jean Genet, cuja real importância (Raul Cortez fazia o primeiro nu do teatro brasileiro, por exemplo) não captou então.

Em 1970, Leonor saiu do Brasil julgando não ser país onde gostasse de viver, impressionada com o banquete para radiologistas no Hotel Quitandinha, em Petrópolis, e tantos policiais em motos para patrulhar os ônibus da comitiva na ida e volta à cidade. De 1975 a 1979, porém, se radicou em São Paulo, onde o marido se tornou professor da Pontifícia Universidade Católica (PUC) e sócio de escritório de advocacia. Quanto a ela,

Vistas bem as coisas, a grande revolução foi a chegada ao Brasil, a descoberta da vida rasgada, ali clandestinamente à minha espera. Eu, de olhos abertos de pasmo, sem imaginar que construção teria o futuro, porque nunca antes tinha pensado senão na continuidade serena de todas as coisas, para sempre. [...]

Desde Lisboa tinha voado entre aventura e adrenalina, sem previsão de regresso. Nas minhas próprias forças e na parceria de emoções com o Alberto eu me sustentava, na mais completa ignorância da crua dimensão das coisas. Ele tinha seguido o impulso de mudança para uma vida diferente, e eu aderia sem hesitar às decisões do meu marido nas questões essenciais. (XAVIER, 2018, p. 134)

A família recém-chegada morou na casa da amiga de uma amiga portuguesa que imigrara antes. A acolhida num apartamento nos Jardins se deu por custo mínimo, quase um mês, até garantir trabalho e documentos. Fixaram-se em Perdizes, perto da PUC. As impressões iniciais do Brasil incluíam contrastes no vocabulário, alimentação e acesso ao crédito (mais restrito em Portugal). "Tudo isto é uma aventura apaixonante, é começar outra vez a vida, comer coisas diferentes, fazer outros hábitos e outra rotina", diria (XAVIER, 2018, p. 138), ressaltando a chance de recomeçar a vida. Um coquetel de boas-vindas no tradicional Clube Pinheiros foi o marco inicial de uma relação de débito com o Brasil: "Nesse dia iniciou-se a minha dívida de gratidão ao Brasil, acrescida de juros e correção monetária que nem até ao fim da vida serei capaz de acertar" (XAVIER, 2018, p. 145). 
Em São Paulo, viveu quatro anos "decisivos na minha história de mulher" (XAVIER, 2018, p. 221) nos quais passou de dona de casa com rede crescente de contatos para professora particular de francês e revendedora porta a porta de plásticos (Tupperware ${ }^{\circledR}$ ) e, depois, cosméticos $\left(\mathrm{Jafra}^{\circledR}\right)$. A reinvenção teve fontes como o exemplo da empregada Marlene, baiana de 19 anos com quem diz ter aprendido autoestima, independência sem raiva e desrespeito, liberdade na fala e execução de tarefas braçais sem subserviência. Aprendia ainda a sociedade de consumo, enquanto Portugal experimentava a democracia.

Estima-se que de 30 a 40 mil portugueses imigraram no Brasil em 1975 e 1976 a própria Leonor ilustraria que tal imigração não seria definitiva. A maior presença lusa era notável para a família, com menor autoimagem de estrangeira, como relatou em carta de 7 de outubro de 1975 para uma amiga, transcrita logo abaixo:

Estou impressionada com a intensidade do fluxo para aqui. Em Março, Abril, fomos quase dos primeiros. Demo-nos logo com brasileiros e foi bom. Ainda falávamos dos Brasileiros como "eles", éramos estrangeiros. Agora tudo isso mudou. No domingo encontrei vinte e nove portugueses na missa. Em cinco quarteirões vivem dezassete famílias aqui em Perdizes. Pessoas que saíram à míngua de emprego e de estabilidade, que não têm nada a ver com ministros.

$[\ldots]$

São Paulo tornava-se centro de comunicação em linha directa com o Rio, e ponto de passagem de muitos portugueses. O espaço das casas foi partilhado, ampliando-se os quartos como instalações provisórias de amigos de amigos, que mandavam recado ou simplesmente apareciam para ficar. Falava-se na primeira pessoa do singular, muitos então enfrentaram a si próprios, e pela primeira vez deixaram o fingimento, o disfarce, a formalidade. Muitos também aprenderam a ouvir os outros, atenuando o seu egoísmo e a visão elitista que tinham do mundo. (XAVIER, 2018, p. 158)

Ampliou horizontes em contato com cidadãos de outros países e no consumo de bens culturais: "A minha cultura geral era limitada, cultura de uma nota só” (XAVIER, 2018, p. 163). A grande expectativa na primeira ida a Portugal, visitado no inverno de 1977/78, atestou a saudade: "Portugal é um encontro de amantes, no meu desejo: 'O coração pula-me por pensar que faltam oito semanas"' (XAVIER, 2018, p. 205). Sentia-se adaptada após dois anos de Brasil, tempo que lhe deixou à vontade nas questões fundamentais e ciente de onde (e com quem) obter outras respostas. Não desperdiçou oportunidades de ter experiências novas.

A disposição de viver novidades e diferenças é exemplificada na ida ao carnaval carioca de 1976, quando viu o desfile de escolas de samba; em outros anos, desfilaria. Para o escritor e diplomata aposentado Marcello Duarte Mathias,

Esta rendição moral à emoliente realidade brasileira, que acompanha a lenta eclosão de uma outra identidade, paralela à portuguesa e dela tão diferente, é o aspecto mais instrutivo destas memórias. A burguesinha crescida dentro dos parâmetros de uma 
Lisboa tradicional, tão burguesmente educada e casada, mergulhada de súbito no universo sem fronteiras da vida brasileira! Vai-se menineira para o Brasil, de lá se vem mulher. É o lado tocante deste livro: a dívida de gratidão ainda emocionada de quem não se esquece das seduções em tempos vividas. Todo o livro de memórias é uma ponta lançada entre várias margens. (MATHIAS, 2015)

A eclosão de outra identidade perpassa As casas contadas, onde a autora citou a ideia do filósofo Agostinho da Silva - imigrante no Brasil de 1947 a 1969 - de que os portugueses se soltaram no país por descobrirem um espaço exterior igual a seu espaço interior. "As mulheres foram as primeiras a descobri-lo" (XAVIER, 2018, p. 186), acrescentaria Leonor.

No Rio, para onde se mudou em 1979 quando Alberto abriu escritório na cidade, a interação entre imigrantes portugueses podia ser tão intensa que muitos se alhearam a temas brasileiros, o que gerou autocrítica em Leonor, sobretudo pelo contraste aos anos iniciais em São Paulo (após Perdizes, morou no bairro Brooklin Paulista, onde o contato com três famílias portuguesas lhe marcaria pelas origens, amigos e referências comuns). Chegou a equiparar a mudança a uma emigração para um local com colônia portuguesa de mentalidade restrita, fechada ao que fosse brasileiro, sempre em grupo e a dizer mal.

Morando em Ipanema e depois Botafogo, fez-se jornalista, escrevendo para leitores no Brasil (O Mundo Português, Jornal do Brasil e revista Manchete) e Portugal (Diário de Notícias, Tempo e revista Espaço T Magazine). Como escritora, os primeiros livros foram o ensaio Atmosferas (1980), Entrevistas (1982, com 46 entrevistas) e o romance Ponte aérea (1983). Na autobiografia, situou nesta fase sua primeira carta em português do Brasil, outro sinal da adaptação, e a volta de muitos portugueses para o país.

Leonor avaliou em 1983 que sua vida pública ia bem, mas a particular, mal, com um crescente desencontro de interesses no casal. "A mudança de país e de mentalidade ia fracturando a unidade que afirmamos, na celebração do casamento. As diferenças acentuavamse por andanças opostas no dia-a-dia" (XAVIER, 2018, p. 266). A imigração e seus efeitos eram responsabilizados pela crise que levaria à separação no ano seguinte.

A reinvenção operou mudanças não só íntimas: ela foi a um ato das Diretas-Já, mostrando que o acúmulo da nacionalidade brasileira não foi mera formalidade. A volta a Lisboa em 1987 foi um reencontro com uma identidade não perdida, que se somou à nova. A decisão veio após cobrir a visita do presidente Mário Soares ao Brasil e ver que sua brasilidade não era maior do que sua identidade de origem. Escreveria a uma amiga:

[...] estou cansada de ficar aqui. O Rio não é uma cidade para uma mulher como eu, no futuro. Descobri que a razão profunda do que me está a acontecer. É não ter sido eu a escolher virmos para o Brasil. Ouve: Resolvi voltar a Lisboa. Tudo isto me tem posto numa ansiedade. A decisão está tomada. Vou aí procurar uma casa. (XAVIER, 2018, p. 301) 
Em congresso sobre a mulher imigrante em 2011, Leonor citaria Ruth Escobar, a economista Maria da Conceição Tavares e a dramaturga Maria Adelaide Amaral — três imigrantes no Brasil - como mulheres exemplares da diáspora portuguesa. Expôs ideias sobre mulheres migrantes que, como ela e Ruth, encontrariam na imigração uma forma de se reinventarem. Trata-se de um depoimento sob medida para concluir esta seção:

Hoje, as mulheres portuguesas deixaram, em absoluto, de corresponder ao modelo da dedicação exclusiva ao casamento, à maternidade, ao serviço e ordenamento da casa. Quando emigram, libertam-se dos parentescos e vizinhanças que tantas vezes ainda nas suas terras de origem as condicionam. Nos países de destino, as menos qualificadas valorizam-se e ganham conhecimentos para melhorar a sua condição no trabalho. Aprendendo auto-estima e concorrência, lutam por funções de chefia, querem alcançar lideranças, anular as desigualdades.

Crescendo na sociedade, descobrem-se a conviver com o diferente, tomam consciência de justos direitos adquiridos, experimentam a partilha de tarefas domésticas. Elas tomam cuidados de saúde, seguem métodos de planeamento familiar, acompanham a adaptação dos filhos aos códigos da sociedade onde passaram a viver. (XAVIER, 2011)

\section{Considerações finais}

As portuguesas Ruth Escobar e Leonor Xavier - uma imigrante permanente e outra provisória - publicaram autobiografias que documentaram a imigração no Brasil e seus efeitos em suas vidas e nas de portugueses e brasileiros com quem conviveram em São Paulo e no Rio de Janeiro. Os balanços de suas histórias apresentam visões argutas que merecem atenção de quem estuda imigração e outras questões como o feminismo.

Ruth Escobar registrou o misto inicial de dor e excitação vivido na imigração, que ela diria garantir uma nova forma de existir, com crueldades, dificuldades e desafios. Para superar tais desafios, contou com o acesso à comunidade portuguesa em São Paulo, fosse para atrair um patrocinador a uma viagem ao Oriente (divisor de águas em sua vida pessoal) ou arrecadar fundos para erguer seu teatro. Um título na Folha de S. Paulo a definiu como "mulher possuída pelo desafio" ainda em 1981, e a sequência de sua vida atesta não ser um epíteto exagerado, tanto pela propensão a se desafiar sempre como pelo exemplo de luta para ampliar espaços e direitos da mulher. A raiz portuguesa, como se lê na obra, gerou uma autoimagem que a acompanhou e a estimulou nessa luta.

Imigrar também aparece como um recomeço de vida na autobiografia de Leonor Xavier. Após sair de Lisboa, foi deixando o papel de coadjuvante no casal e encontrou protagonismo como mãe, jornalista e escritora. Devido a sua reinvenção pessoal, diria ter uma dívida de gratidão com o país onde viveu 12 anos. Do convívio com brasileiros e seus compatriotas emigrados, extraiu memórias e ideias para si e os/as leitores/as. 
Ruth Escobar e Leonor Xavier foram hábeis em comunicar sentimentos vividos na imigração e tantos outros. Ao comporem narrativas ricas sobre suas vidas, lançaram luz a continuidades e mudanças compartilhadas em menor ou maior grau por quem, a exemplo delas, também transitou entre duas margens lusófonas do Atlântico.

\section{Referências}

BAPTISTA, António A. Emigração e expressão literária em Leonor Xavier. In: XAVIER, Leonor. Falar de viver. São Paulo: Difel, 1986. p. IX-XI.

ESCOBAR, Ruth. Maria Ruth. Rio de Janeiro: Guanabara, 1987.

FREITAS, Sônia Maria de. Presença portuguesa em São Paulo. São Paulo: Imprensa Oficial do Estado de São Paulo/Memorial do Imigrante, 2006.

GASMAN, Nadine. Nota de pesar da ONU Mulheres pelo falecimento Ruth Escobar. ONU Mulheres. 7 out. 2017. Disponível em: www.onumulheres.org.br/noticias/nota-de-pesar-daonu-mulheres-pelo-falecimento-ruth-escobar/. Acesso em: 26 nov. 2019.

LOBO, Eulália M. L. Imigração portuguesa no Brasil. São Paulo: Hucitec, 2001.

MATHIAS, Marcello Duarte. Diário da Abuxarda: 2007-2014. Lisboa: D. Quixote, 2015.

MENDES, Oswaldo. Rute Escobar, uma mulher possuída pelo desafio, Folha de S. Paulo, São Paulo, p. 45, 2 ago. 1981. Disponível em: https://acervo.folha.com.br/leitor.do?numero=7756 Acesso em: 26 nov. 2019.

XAVIER, Leonor. Falar de viver. São Paulo: Difel, 1986.

. Novos domínios de afirmação da mulher na diáspora. Mulher migrante em congresso. Espinho, 2011. Disponível em: mulhermigranteemcongresso.blogspot.com/2011/11/leonorxavier-painel-cidadania-e.html. Acesso em: 26 nov. 2019.

. Portugueses do Brasil e brasileiros de Portugal. Alfragide: Oficina do Livro, 2016. . Casas contadas [2009]. Alfragide: Bis, 2018.

\section{Minicurrículo}

Mario Luis Grangeia é doutor em Sociologia (UFRJ), especialista em Sociologia Política e Cultura (PUC-Rio) e autor de estudos para a Escola Superior do Ministério Público da União, onde é líder adjunto do grupo de pesquisa Movimentos Sociais, e para o Centro Nacional de Cultura (Portugal) e Fundação Biblioteca Nacional, onde fez projetos na raiz deste artigo. Autor de Brasil: Cazuza, Renato Russo e a transição democrática (Rio de Janeiro: Civilização Brasileira, 2016). 